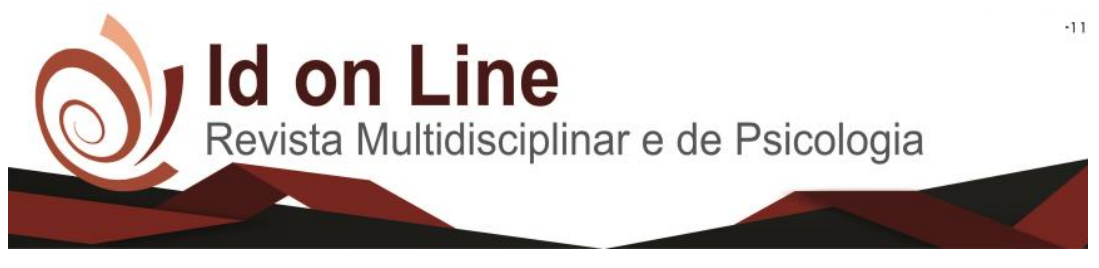

DOI: 10.14295/idonline.v13i46.1992

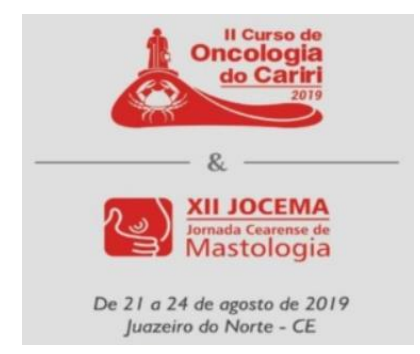

Resumo

\title{
DIETOTERAPIA NA EQUIPE MULTIDISCIPLINAR PARA O TRATAMENTO DE CÂNCER DE MAMA
}

\author{
Ana Clara Lacerda Cervantes de Carvalho ${ }^{\text {; }}$ Waldeir de Souza Ferreira Júnior ${ }^{1}$; \\ Suanam Altair Tavares de Menezes ${ }^{\prime}$; Mariana Machado Bueno ${ }^{2}$.
}

Introdução: o câncer de mama é uma das principais neoplasias que mais acometem mulheres no Brasil, estimando 59.700 novos casos nos anos de 2018 e 2019, consiste nas mudanças da expressão do padrão de genes que atuam nas sinalizações das células mamárias provocando várias complicações, como a desnutrição. Objetivo: o objetivo foi analisar a conduta nutricional no tratamento para o câncer de mama ofertado pela equipe interdisciplinar. Método: trata-se de uma revisão sistemática sem metanálise da literatura nas bases de dados LILACS e SCIELO, com buscas realizadas em julho de 2019, utilizando os descritores associados ao operador booleano (AND): Dietoterapia. Multidisciplinar. Câncer de mama. Os critérios de inclusão foram estudos em português e inglês, publicados entre os anos de 2010 a 2018, excluindo os que não estavam disponíveis na integra ou não abordassem o assunto. Resultados: Foram selecionados 14 artigos, após a aplicação dos critérios, restaram 8 artigos. Apesar do bom prognóstico, se diagnosticado precocemente, na saúde pública, verificam-se atrasos dos atendimentos no decorrer do aparecimento dos sintomas e no tratamento, mantendo as taxas de mortalidade elevadas. Por essa razão, a terapia ofertada pela equipe de saúde deve promover o cuidado integral para a compressão íntegra da doença. No âmbito nutricional, o profissional auxilia na redução da sintomatologia causada pela neoplasia e terapêutica, na manutenção do peso, tratando principalmente, a desnutrição, necessitando de maior aporte protéico no consumo pela perda e degradação de massa magra, a deficiência de vitaminas e minerais pelo aumento do gasto consumptivo da doença e na ingesta alimentar insuficiente, ofertando hortaliças e alimentos de baixo teor de gordura, evitando o consumo de embutidos e carnes vermelhas; na diminuição dos efeitos colaterais proporcionados pelos métodos interdisciplinares, dessa forma a avalição nutricional atua para manter o estado adequado do indivíduo e a melhor resposta ao tratamento, sendo utilizada desde a antropometria, exames bioquímicos e avaliação clínica, apesar do caráter extenuante da doença, o sobrepeso e a obesidade são fatores de risco. Conclusão: a terapia nutricional é, portanto, adequada, preconizando as recomendações energéticas, ao tipo de neoplasia, grau de manifestação no paciente e com o estado clínico, sendo fundamental o acompanhamento nutricional em uma equipe de saúde, respeitando a particularidade do paciente.

Palavras-Chave: Dietoterapia. Interdisciplinaridade. Neoplasia mamária.

\footnotetext{
${ }^{1}$ Discente do Curso de Nutrição da Faculdade de Juazeiro do Norte- FJN;

2 Docente do Curso de Nutrição da Faculdade de Juazeiro do Norte- FJN;

Correspondência para lacerdaana00@gmail.com.
} 


\section{Referências:}

ANSTEY, E. H.; SHOEMAKER, M. L.; BARRERA, C. M.; NEIL, M. B., VERMA, A. B.; HOLMAN, D. M. Breastfeeding and Breast Cancer Risk Reduction: Implications for Black Mothers. American Journal of Preventive Medicine, v.53, n.3, 2017. DOI: 10.1016/j.amepre.2017.04.024.

INCA. Coordenação de Prevenção e Vigilância. Estimativa 2018: incidência de câncer no Brasil / Instituto Nacional de Câncer José Alencar Gomes da Silva. Coordenação de Prevenção e Vigilância. - INCA, 2017. Disponível em: <https://www.inca.gov.br/sites/ufu.sti.inca. local/files//media/document//estimativa-incidencia-de-cancer-no-brasil-2018.pdf $>$. Acesso em: 25/07/2019.

NASCIMENTO, F. S. M.; GÓIS, D. N. S.; ALMEIDA, D. S.; NASCIMENTO, A. L.; ALMEIDA, T. C.; GUEDES, V. R. A Importância Do Acompanhamento Nutricional No Tratamento E Na Prevenção Do Câncer. Ciências Biológicas e de Saúde, v.2, n.3, 2015. Disponível em: https://periodicos.set.edu.br/index.php/cadernobiologicas/article/view/ 1787/1183. Acesso em: 25/07/2019.

OLIVEIRA, V. A. Efeitos da imunonutrição no tratamento de pacientes com câncer e suas complicações. Semina: Ciências Biológicas e da Saúde, v. 35, n. 2, 2015. DOI: 10.5433/16790367.201v36n1p107.

OLIVEIRA, M. M.; MALTA, D. C.; GUAUCHE, H.; MOURA, L. SILVA, G. A. Estimativa de pessoas com diagnóstico de câncer no Brasil: dados da Pesquisa Nacional de Saúde, 2013. Revista Brasileira de Epidemiologia, v.18, n. 2, 2015. DOI: 10.1590/1980-5497201500060013.

PANIS, C. et al. Revisão crítica da mortalidade por câncer usando registros hospitalares e anos potenciais de vida perdidos. Revista Einstein (São Paulo), v.16, n.1, 2018. DOI: 10.1590/S1679$45082018 \mathrm{AO} 4018$.

SAMPAIO, H. A. C.; ROCHA, D. C.; SABRY, M. O. D.; PINHEIRO, L. G. P. Consumo alimentar de mulheres sobreviventes de câncer de mama: análise em dois períodos de tempo. Revista de Nutrição, v.5, n.25, 2012. DOI: 10.1590/S1415-52732012000500005.

SILVA, P. B.; LOPES, M.; TRINDADE, L. C. T.; YAMANOUCHI, C. N. Controle dos Sintomas e Intervenção nutricional. Fatores que interferem na qualidade de vida de pacientes oncológicos em tratamento paliativo. Revista Dor, v.11, n.4, 2010. Disponível em: http://files.bvs.br/upload/S/1806-0013/2010/v11n4/a1648.pdf. Acesso em: 25/07/2019.

8 Id on Line Rev. Mult. Psic. V.13, N. 46 p. 7-8, 2019 - ISSN 1981-1179 EDIÇÃO ESPECIAL: ANAIS DO II CURSO DE ONCOLOGIA DO CARIRI E XII JOCEMA - JORNADA CEARENSE DE MASTOLOGIA. JUAZEIRO DO NORTE, 21 A 24 DE AGOSTO DE 2019. Edição eletrônica em http://idonline.emnuvens.com.br/id 